AKSIOMA: Jurnal Program Studi Pendidikan Matematika

Volume 10, No. 2, 2021, 521-535

DOI: https://doi.org/10.24127/ajpm.v10i2.3480

\title{
ANALISIS KEMAMPUAN MENYELESAIKAN SOAL HIGH ORDER THINKING SKILLS DITINJAU DARI KEMAMPUAN BERPIKIR LOGIS
}

\author{
Wahyuddin $^{1 *}$, Sri Satriani' ${ }^{2}$, Faisal Asfar ${ }^{3}$ \\ ${ }^{1,2}$ Universitas Muhammadiyah Makassar, Indonesia \\ ${ }^{3}$ SMA Negeri 2 Kabupaten Kepulauan Selayar, Indonesia \\ *Corresponding author. Jalan Sultan Alauddin Nomor 258, 90922, Makassar, Indonesia
Email :wahyu@unismuh.ac.id ${ }^{* *}$
srisatriani@unismuh.ac.id ${ }^{2)}$
faisalasfar@gmail.com ${ }^{3)}$

Received 15 January 2021; Received in revised form 26 June 2021; Accepted 28 June 2021

\begin{abstract}
Abstrak
Tujuan penelitian ini untuk menganalisis dan mendeskripsikan kemampuan menyelesaikan soal high order thinking skills (HOTS) ditinjau dari kemampuan berpikir logis. Penelitian ini merupakan penelitian deskriptif dengan pendekatan kualitatif. Subjek penelitian sebanyak 27 siswa kelas XI SMAN 2 Kabupaten Kepulauan Selayar yang dipilih 1 kelas dengan teknik purposive sampling. Pengumpulan data menggunakan tes kemampuan berpikir logis, tes kemampuan menyelesaikan soal HOTS, dan wawancara. Instrumen tes diadopsi dari instrumen baku yang divalidasi ahli. Analisis data menggunakan analisis deskriptif dan hasil wawancara diolah dengan mereduksi, menyajikan, dan penarikan kesimpulan. Hasil penelitian menyimpulkan bahwa kemampuan berpikir logis berada pada kategori rendah sedangkan kemampuan menyelesaikan soal HOTS berada pada kategori sedang. Selanjutnya, aspek kemampuan berpikir logis ditemukan bahwa siswa kategori tinggi (T) mampu memenuhi kriteria level C4, C5, dan C6 sedangkan siswa kategori sedang (S) dan kategori rendah (R) hanya mampu memenuhi kriteria level C4 dan C5. Secara umum siswa masih kesulitan memenuhi level C6 dan kemampuan C6 siswa masih tergolong rendah. Kendala yang dihadapi siswa (S) dan (R) dalam memenuhi aspek C6 yaitu siswa mengalami kesulitan dan kendala dalam menerjemahkan permasalahan kedalam kalimat matematika, siswa belum mampu memberikan cara pandang terhadap suatu persoalan sehingga belum bisa mengeluarkan ide dan merancang solusi secara mandiri untuk menyelesaikan permasalahan dalam mengambil keputusan.
\end{abstract}

Kata Kunci: Berpikir logis; kemampuan HOTS.

\begin{abstract}
The main purpose of this study was to analyze and describe the ability to solve HOTS questions in terms of students' logical thinking abilities. This type of research was a descriptive study with a qualitative approach. The research subjects were 27 students of class XI State Senior High School 2 of Kabupaten Selayar Regency who were selected from 1 class using purposive sampling technique. Data collection techniques used a logical thinking ability test, a test of the ability to solve HOTS questions, and interviews. The test instruments were adopted from standard instruments which were further validated by experts. The results of the study concluded that the students' logical thinking skills were in the low category, while the students' ability to solve HOTS questions was in the medium category. From the aspect of logical thinking ability, it was found that students with high categories were able to meet the criteria of $\mathrm{C4}, \mathrm{C5}$, and C6 while students with medium categories $(S)$ and low categories $(R)$ were only able to meet the criteria of C4 and C5. In general, students still have difficulty meeting the C6 level (creating) and it was still low. The obstacles faced by students $(S)$ and $(R)$ in fulfilling aspects of C6 were students experiencing difficulties in translating problems into mathematical sentences and have not been able to provide a perspective so that they cannot issue ideas and design solutions independently to solve problems in making decisions.
\end{abstract}

Keywords: HOTS ability; logical thinking.

This is an open access article under the Creative Commons Attribution 4.0 International License 


\section{PENDAHULUAN}

Salah satu program pendidikan yang tepat untuk menjawab tantangan revolusi industry 4.0 adalah melalui pendidikan sains, teknologi, teknik, dan matematika (STEM), (Kirchner, 2017). Matematika sangat berperan dalam perkembangan teknologi dan komputer seperti pembuatan perangkat lunak dari generasi kegenarasi diprakarsai oleh ahli matematika dan ahli logika, (Konda, 2020). Demikian juga yang ungkapkan oleh (Toheri \& Muchyidin, 2019) bahwa sejak dini siswa harus dipersiapkan dengan pengetahuan matematika yang kuat untuk dapat menguasai dan menciptakan teknologi di masa depan. Matematika mampu mempersiapkan SDM kebutuhan masa depan karena matematika merupakan pelayan ilmu, mengkaji pola hubungan, menumbuhkan intuisi dan penemuan, sebagai alat pemecah masalah, serta sebagai alat komunikasi, (Priatna \& Yuliardi, 2019).

Untuk mewujudkan siswa memiliki kemampuan berpikir kritis dan kemampuan pemecahan masalah, maka siswa harus dilatih dengan kemampuan berpikir pada level tingkat tinggi, (Supendi \& Nurjanah, 2019). Pemikiran tingkat tinggi dalam matematika harus dikuasai siswa agar mampu menganalisis, mengumpulkan bukti, dan membangun argumen serta menciptakan gagasan, (Lewis \& Smith, 2011). Berpikir tingkat tinggi atau HOTS merupakan interpretasi dari berpikir kompleks dalam mengkritisi, memberi solusi, dan pemecahan masalah, (Budiarta et al., 2018), kemampuan menghubungkan, memanipulasi, dan mentransformasikan pengetahuan sebagai pengalaman berpikir kritis, logis, metakognitif, reflektif, dalam situasi baru (Nisa et al., 2018) dan (Permana et al., 2020).
Dengan HOTS, maka siswa dapat mengembangkan wawasan baru, berkomunikasi dengan baik, bahkan berdebat dengan keterampilan berpikir tingkat tinggi, (Chinedu \& Kamin, 2015) dan (Widana et al., 2018); meningkatkan keterampilan berpikir, (Setiawan et al., 2018); mengola informasi yang efektif dan efesien, (Tan \& Halili, 2015); (Yee et al., 2015); dan (Purwanti, 2020); meningkatkan penalaran deduktif, (Misrom et al., 2020); meningkatkan prestasi dan keterampilan, (Sulaiman et al., 2017); serta mengantarkan siswa mencapai kesuksesan, (Tanujaya et al., 2017).

Faktor lain yang sangat diperlukan dalam kemampuan matematika adalah berpikir logis sebagaimana dijelaskan dalam (Permendiknas RI No. 22 Tahun 2006 Tentang Standar Isi Untuk Satuan Pendidikan Dasar Dan Menengah, 2006) bahwa pembelajaran matematika membekali peserta didik dengan kemampuan berpikir logis. Demikian juga yang dikemukakan (Fitriana et al., 2015) bahwa berpikir logis merupakan kemampuan esensial yang perlu dimiliki dalam belajar matematika.

Namun kenyataan yang terjadi saat ini belum sesuai dengan apa yang diharapkan, rendahnya kemampuan berpikir tingkat tinggi siswa ditemukan masih banyak permasalahan seperti pengajaran HOTS di kelas masih jarang, (Tonra et al., 2019); pembelajaran HOTS dalam Kurikulum 2013 tidak menunjukkan proporsi ideal, (Sutrisno et al., 2020); kebiasaan berpikir tingkat rendah yang diajarkan kepada siswa menyebabkan tidak memiliki high order thinking skills, (Rochman \& Hartoyo, 2018); pengetahuan dan pemahaman guru tentang HOTS masih rendah, (Retnawati et al., 2018); (Driana \& Ernawati, 2019); (Saraswati \& Agustika, 
2020); guru mengalami kesulitan dalam merancang asesmen HOTS, (Suratmi et al., 2020); keterampilan literasi sains siswa pada kategori rendah, (Mardhiyyah et al., 2016); dan hasil HOTS masih rendah, (Shidiq et al., 2015); (Kusuma et al., 2017); (Suhirman et al., 2020); dan (Zaiyar \& Rusmar, 2020).

Permasalahan secara umum tersebut juga terjadi di SMA Negeri 2 Kabupaten Kepulauan Selayar, dimana nilai ulangan semester matematika masih kategori berada pada kategori sedang dan hasil UN 2019 hanya rata-rata 31,35. Dalam hal proses pembelajaran juga dilaksanakan secara rutin tanpa mengembangkan materi dan soal HOTS, siswa juga jarang bahkan hampir tidak pernah diikutkan dalam lomba matematika tingkat regional dan nasional, demikian halnya juga dengan media pembelajaran berbasis HOTS seperti modul dan lembar kerja siswa yang masih sangat terbatas.

Sudah banyak penelitian terdahulu yang membahas tentang HOTS, seperti (Annizar et al., 2020) yang meneliti proses berpikir inkuiri dalam menyelesaikan masalah (HOTS) ditinjau dari tingkat kognitif; (Aliyanti et al., 2019) yang menganalisis kesalahan representasi simbolik dalam menyelesaikan Soal HOTS; dan (Hasyim \& Andreina, 2019) yang menganalisis HOTS siswa dalam menyelesaikan soal open ended. Namun dari penelitian terdahulu yang relevan, masih belum ada yang mengaitkan antara HOTS dengan kemampuan berpikir logis siswa.

Padahal penelitian yang berkaitan
dengan analisis kemampuan
menyelesaikan soal HOTS ditinjau dari
kemampuan berpikir logis siswa penting
dilakukan dengan harapan dapat
memberikan prototipe tentang kemampuan

siswa menyelesaikan soal HOTS ditinjau dari kemampuan berpikir logis. Selain itu temuan penelitian dapat dijadikan rujukan dalam pengembangan kemampuan HOTS siswa dalam menunjang peningkatan hasil belajar matematika. Hasilnya juga dapat menjadi referensi bagi dosen dan guru dalam pengembangan kualitas dan hasil pembelajaran matematika. Oleh karena itu, tujuan utama penelitian ini adalah untuk menganalisis dan mendeskripsikan kemampuan menyelesaikan soal HOTS ditinjau dari kemampuan berpikir logis siswa.

\section{METODE PENELITIAN}

Penelitian ini merupakan penelitian deskriptif dengan pendekatan kualitatif. Tahapan penelitian meliputi: 1) Persiapan dengan penentuan masalah berdasarkan fakta dilapangan, melakukan studi literatur, penetapan subjek penelitian, penetuan metode, dan penyusunan dan falidasi instrument; 2) Pelaksanaan penelitian meliputi pengumpulan data dilapangan; dan 3) Penyusunan laporan dengan analisis data, penarikan kesimpulan, dan penyusunan laporan penelitian.

Subjek penelitian yaitu siswa kelas XI SMAN 2 Kabupaten Kepulauan Selayar dengan sampel sebanyak 27 orang yang dipilih dari 1 kelas dengan teknik purposive sampling. Selanjutnya dari 27 orang kemudian dipilih 3 orang yang mewakili kriteria tinggi, sedang, dan rendah dalam hal kemampuan berpikir logis.

Teknik pengumpulan data menggunakan tes kemampuan berpikir logis yang terdiri dari 30 soal pilihan ganda yang dikembangkan dari dua indikator yaitu berpikir induktif dan berpikir deduktif, instrument diadopsi dari 
instrument baku (Wahyuddin, 2013). Selanjutnya tes kemampuan menyelesaikan soal HOTS dengan instrumen yang diadopsi (Misri \& Kamelia, 2018); dan (Toheri \& Muchyidin, 2019) yang selanjutnya divalidasi oleh ahli.

Teknik analisis data menggunakan analisis deskriptif dengan menggunakan keriteria pada Tabel 1 dan Tabel 2, sedangkan hasil wawancara dioleh dengan mereduksi data, menyajikan data, dan penarikan kesimpulan.

Tabel 1. Kategori tingkat kemampuan berpikir logis dan kemampuan HOTS

\begin{tabular}{cc}
\hline Nilai & Tingkat Kemampuan \\
\hline$>87$ & Sangat Tinggi \\
$75-86$ & Tinggi \\
$63-74$ & Sedang \\
$50-62$ & Rendah \\
$<50$ & Sangat Rendah \\
\hline
\end{tabular}

(Purwanto, 2012)

Tabel 2. level kognitif dan indikator kognitif HOTS

\begin{tabular}{ll}
\hline $\begin{array}{l}\text { Level Kognitif } \\
\text { HOTS }\end{array}$ & \multicolumn{2}{c}{ Definisi } \\
\hline $\begin{array}{l}\text { C4- } \\
\text { Menganalisis }\end{array}$ & $\begin{array}{l}\text { Mampu mencermati materi } \\
\text { kemudian } \\
\text { kaitannya } \\
\text { keseluruhan. } \\
\text { secara }\end{array}$ \\
Membedakan & $\begin{array}{l}\text { Mampu memilah dan } \\
\text { membedakan informasi } \\
\text { relevan dan tidak relevan. }\end{array}$ \\
Mengorganisasi & $\begin{array}{l}\text { Mampu mengidentifikasi } \\
\text { informasi menjadi struktur }\end{array}$ \\
Mengartibusi & $\begin{array}{l}\text { Mang terorganisir. } \\
\text { hubungan menentukan pola } \\
\text { tiap struktur informasi. bagian }\end{array}$ \\
Kegiatan membuat suatu \\
keputusan berdasarkan \\
Mengevaluasi \\
kriteria dan standar yang \\
telah ditentukan.
\end{tabular}

\begin{tabular}{|c|c|}
\hline $\begin{array}{c}\text { Level Kognitif } \\
\text { HOTS }\end{array}$ & Definisi \\
\hline Memeriksa & $\begin{array}{l}\text { Mampu mengecek dan } \\
\text { menentunkan bagian yang } \\
\text { salah terhadap proses atau } \\
\text { pada sebuah pernyataan. }\end{array}$ \\
\hline Mengkritik & $\begin{array}{l}\text { Mampu melakukan } \\
\text { penerimaan dan penolakan } \\
\text { terhadap informasi melalui } \\
\text { kriteria yang telah } \\
\text { ditetapkan. }\end{array}$ \\
\hline C6-Mencipta & $\begin{array}{l}\text { Membentuk solusi atau } \\
\text { seseuatu yang baru dari } \\
\text { kegitan } \\
\text { mengabungkan berbagai } \\
\text { elemen. }\end{array}$ \\
\hline Merumuskan & $\begin{array}{l}\text { Mampu memberikan cara } \\
\text { pandang terhadap suatu } \\
\text { persoalan. }\end{array}$ \\
\hline Merencana & $\begin{array}{l}\text { Mampu merancang suatu } \\
\text { cara untuk menyelesaikan } \\
\text { masalah }\end{array}$ \\
\hline Memproduksi & $\begin{array}{l}\text { Mampu membuat ide, } \\
\text { solusi atau keputusan dari } \\
\text { rancangan yang dibuat } \\
\text { sebelumnya. }\end{array}$ \\
\hline
\end{tabular}

(Saraswati \& Agustika, 2020)

\section{HASIL DAN PEMBAHASAN}

Data kemampuan berpikir logis diukur dengan dua indikator yaitu berpikir induktif dan berpikir deduktif kemudian dikemas dalam tes yang terdiri dari 30 soal pilihan ganda sedangkan kemampuan menyelesaikan soal HOTS diukur dengan 3 indikator kemampuan kognitif yaitu level C4 (menganalisis), C5 (mengevaluasi), dan C6 (mencipta) yang dibuat dalam tes dengan 3 soal essay tentang matriks.

Data hasil tes selanjutnya dianalisis dengan analisis deskriptif disajikan pada Tabel 3. 
AKSIOMA: Jurnal Program Studi Pendidikan Matematika

Volume 10, No. 2, 2021, 521-535

DOI: https://doi.org/10.24127/ajpm.v10i2.3480

Tabel 3. Hasil analisis deskriptif

\begin{tabular}{ccc}
\hline Nilai & $\begin{array}{c}\text { Kemampuan } \\
\text { Bepikir Logis }\end{array}$ & $\begin{array}{c}\text { Kemampuan } \\
\text { HOTS }\end{array}$ \\
\hline Mean & 60.19 & 71.41 \\
Median & 60.00 & 67.00 \\
Modus & 60 & 67 \\
Std. & 3.050 & 3.369 \\
Error & 15.850 & 17.504 \\
Stdev & 56 & 67 \\
Range & 27 & 33 \\
Min & 83 & 100 \\
Max & \multicolumn{4}{c}{ Berdasarkan Tabel 3} & diperoleh \\
informasi bahwa kemampuan berpikir \\
logis siswa dengan nilai rata-rata 60,19 \\
atau berada pada kategori rendah \\
sedangkan kemampuan menyelesaikan \\
soal HOTS dengan nilai rata-rata 71,41 \\
atau berada pada kategori sedang. \\
Selanjutnya sebaran distribusi hasil tes \\
siswa disajikan pada Tabel 4. Berdasarkan \\
Tabel 4 diperoleh informasi bahwa \\
kemampuan berpikir logis siswa
\end{tabular}

didominasi siswa dengan kategori sedang dan rendah sedangkan kemampuan menyelesaikan soal HOTS didominasi siswa dengan kategori sedang.

Tabel 4. Sebaran distribusi hasil tes

\begin{tabular}{ccccc}
\hline \multirow{2}{*}{ Kriteria } & \multicolumn{2}{c}{$\begin{array}{c}\text { Kemampuan } \\
\text { Bepikir Logis }\end{array}$} & \multicolumn{2}{c}{$\begin{array}{c}\text { Kemampuan } \\
\text { HOTS }\end{array}$} \\
\cline { 2 - 5 } Jumlah & \% & Jumlah & \% \\
\hline Sangat & 0 & 0 & 6 & 22,22 \\
Tinggi & 5 & 18,52 & 4 & 14,81 \\
Tinggi & 5 & 29,63 & 14 & 51,85 \\
Sedang & 8 & 1 & 3,70 \\
Rendah & 8 & 29,63 & 1 & 7,41 \\
Sangat & 6 & 22,22 & 2 & \\
Rendah & & & & 100 \\
Jumlah & 27 & 100 & 27 & \\
\hline
\end{tabular}

Selanjutnya hasil analisis kemampuan menyelesaikan soal HOTS diuraikan diuraikan pada pembahasan soalsoal berikut.

Tabel 5. Soal dan keterangan

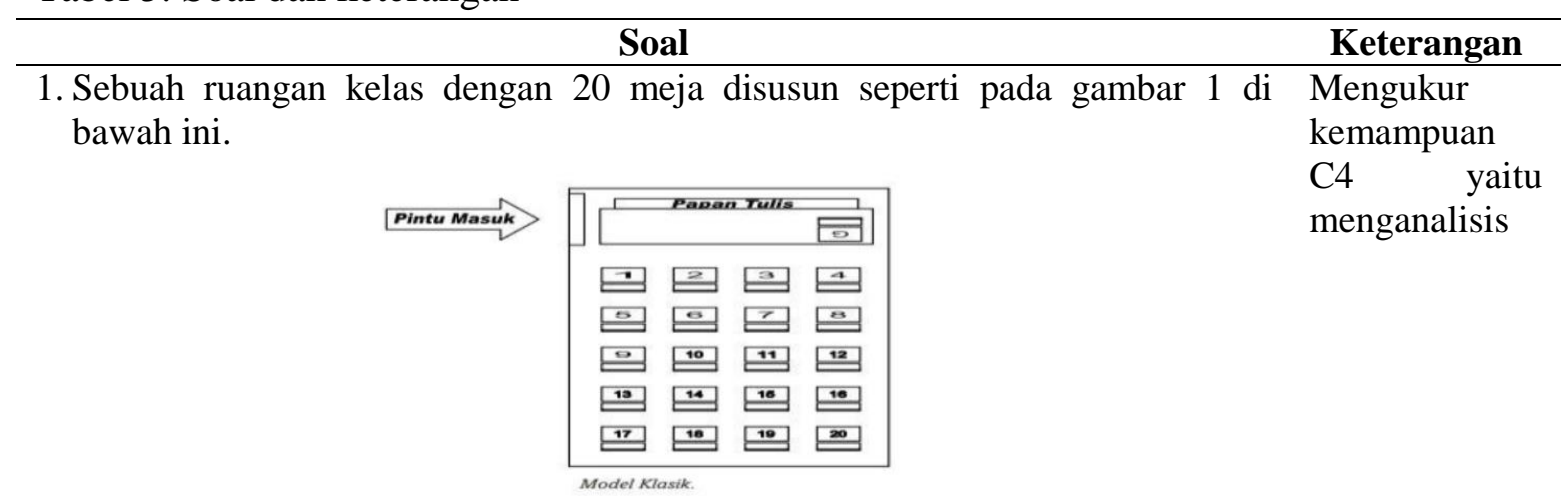

Gambar 1. Ilustasi soal 1

Berapa ordo dari denah meja pada gambar tersebut, apabila meja dianggap elemen dari matriks? Jelaskan pendapat anda!

2. Diberikan sebuah matriks $\mathrm{A}=\left[\begin{array}{ll}a & b \\ c & d\end{array}\right]$ jika matriks $\mathrm{B}$ yang anggotanya merupakan anggota dari matriks A dengan menukarkan baris pertama dengan baris ke dua. Maka,
a. Tentukan determinan A dan determinan B. Jelaskan pendapat anda!
b. Jelaskan hubungan antara determinan A dan determinan B!

Mengukur kemampuan

C5 mengevaluasi 


\section{Soal}

3. Radio A FM melakukan acara amal dengan mengumpulkan sumbangan dari pendengar setianya. Sebagai pendengar setia radio tersebut, Bimo akan menyumbangkan sejumlah uang berdasarkan komposer lagu favoritnya untuk tiga hari ke depan. Setiap kali lagu favoritnya diputarkan, Bimo akan menyumbangkan: Rp 30.000,- untuk lagu Aril Noah; Rp 25.000,- untuk setiap lagu Judika, dan Rp 20.000,- untuk setiap lagu Wali. Informasi jumlah komposer lagu favorit yang diputar selama tiga hari berturut-turut disajikan pada Tabel 6 dan 7.

Tabel 6. Jumlah komposer musik favorit yang didengar Bimo selama 3 hari

\begin{tabular}{cccc}
\hline & Senin & Selasa & Rabu \\
\hline Noah & 4 & 3 & 5 \\
Judika & 3 & 2 & 4 \\
Wali & 2 & 3 & 3 \\
\hline
\end{tabular}

Tabel 7. Jumlah uang yang akan disumbangkan

\begin{tabular}{cccc}
\hline & Noah & Judika & Wali \\
\hline $\begin{array}{c}\text { Banyaknya } \\
\text { Sumbangan }\end{array}$ & 30.000 & 25.000 & 20.000 \\
\hline
\end{tabular}

Jika Bimo memiliki uang sebesar Rp 770.000, maka:

a. Berapa jumlah uang yang disumbangkan Bimo pada hari pertama (Senin), hari kedua (Selasa), dan hari ketiga (Rabu). Jelaskan pendapat anda!

Sebutkan salah satu lagu yang masih bisa diputar satu kali. Jelaskan pendapat anda!

Soal nomor 1 digunakan untuk mengukur kemampuan $\mathrm{C} 4$ yaitu menganalisis, membedakan, mengorganisasi, dan mengartibusi. Soal tersebut berbasis permasalahan kontekstual dan menarik (contextual and trending topic) serta dibutuhkan kemampuan untuk menghubungkan informasi posisi meja dengan ordo matriks. Untuk menjawab soal tersebut diperlukan kemampuan untuk menganalisis antara baris dan kolom serta kaitannya dengan matriks yang selanjutnya diperlukan kemampuan mengorganisasi yaitu membedakan baris dan kolom serta menentukan pola hubungan antara informasi tersebut melalui kemampuan mengatribusi.
Berdasarkan hasil tes diperoleh bahwa secara keseluruhan atau sebanyak 27 orang siswa dapat menjawab soal tersebut dengan benar. Dengan demikian, maka aspek C4 siswa yaitu menganalisis sudah terpenuhi.

Selanjutnya, soal nomor 2 untuk mengukur kemampuan C5 mengevaluasi, memeriksa, dan mengkritik. Untuk menjawab soal terbut diperlukan kemampuan mengevaluasi untuk membentuk suatu matriks baru yaitu matriks B yang terbentuk dari elemenelemen matriks A. Serta dibutuhkan kemampuan memeriksa dan mengeritik untuk menjelaskan hubungan antara determinan matriks $\mathrm{A}$ dan determinan 
matriks B. Berdasarkan hasil tes diperoleh 23 orang $(85,18 \%)$ yang menjawab dengan benar, 3 orang $(11,11 \%)$ mampu memahami soal namun tidak mampu menjawab dengan benar, dan 1 orang $(3,70 \%)$ sama sekali tidak menjawab karena tidak memahami soal. Dengan demikian, maka aspek C5 siswa yaitu mengevaluasi sudah terpenuhi secara keseluruhan dan sudah masuk dalam kategori tinggi.

Selanjutnya, soal nomor 3 untuk mengukur kemampuan C6 mencipta dan merumuskan. Untuk menjawab soal terbut diperlukan kemampuan mencipta yaitu membentuk solusi dari permasalahan yang ada dengan mengabungkan berbagai informasi dan menciptakan suatu langkah dan menentukan suatu rumus relevan dan memberikan cara pandang terhadap persoalan tersebut. Berdasarkan hasil tes diperoleh bahwa terdapat $6(22,22 \%)$ yang memahami soal dan mampu menjawab dengan benar, 16 orang $(59,26 \%)$ yang memahami tentang apa yang ditanyakan dalam soal namun tidak bisa menjawab dengan benar, dan $5(18,52 \%)$ yang sama sekali tidak memahami soal dan tidak memberi jawaban. Dengan demikian, maka aspek C6 siswa yaitu mencipta belum terpenuhi dan masih berada pada kategori rendah. Secara keseluruhan, hasil tes kemampuan menyelesaikan soal HOTS disajikan pada Tabel 8.

Tabel 8. Hasil tes level kognitif HOTS

\begin{tabular}{|c|c|c|}
\hline $\begin{array}{l}\text { Tingkatan } \\
\text { Kognitif }\end{array}$ & $\begin{array}{c}\text { Persentase } \\
\%\end{array}$ & Kategori \\
\hline C4 (Menganalisis) & 100 & Sangat Tinggi \\
\hline C5 (Mengevaluasi) & 85,18 & Tinggi \\
\hline C6 (Mencipta) & 22,22 & Sangat Rendah \\
\hline Selanjutnya & untuk & mengetahui \\
\hline
\end{tabular}

maka dipilih 3 siswa yang masing-masing mewakili kategori tinggi $(\mathrm{T})$, sedang (S), dan rendah $(\mathrm{R})$ dalam kemampuan berpikir logis untuk diwawancarai lebih mendalam guna mendapat-kan informasi yang lebih detail. Adapun kategori sangat tinggi tidak terwakili karena tidak ada siswa yang masuk kategori tersebut, sedangkan kategori sangat rendah tidak diteliti dengan pertimbangan bahwa siswa yang masuk kategori tersebut disinyalir tidak dapat memberikan data dengan baik dan akurat.

Untuk hasil analisis keterkaitan antara kemampuan berpikir logis dan kemampuan menyelesaikan soal HOTS disajikan pada Tabel 9.

Tabel 9. Kemampuan HOTS ditinjau dari kemampuan berpikir logis

\begin{tabular}{cccc}
\hline & \multicolumn{3}{c}{ Kemampuan Berpikir } \\
Level Kognitif & \multicolumn{3}{c}{ Logis } \\
\cline { 2 - 4 } HOTS & $(\mathbf{T})$ & $(\mathbf{S})$ & $\mathbf{( R )}$ \\
\hline C4 (Menganalisis) & $\mathrm{M}$ & $\mathrm{M}$ & $\mathrm{M}$ \\
C5 (Mengevaluasi) & $\mathrm{M}$ & $\mathrm{M}$ & $\mathrm{M}$ \\
C5 (Mencipta) & $\mathrm{M}$ & $\mathrm{TM}$ & $\mathrm{TM}$ \\
\hline
\end{tabular}

Keterangan:

Tinggi (T), Sedang (S), Rendah (R), Menemenuhi (M), dan Tidak Memenuhi (TM).

Berdasarkan Tabel 9 diperoleh informasi bahwa untuk siswa dengan kategori tinggi (T) dalam kemampuan berpikir logis mampu memenuhi level $\mathrm{C} 4$, C5, dan C6, namun siswa dengan kategori sedang $(\mathrm{S})$ dan kategori rendah $(\mathrm{R})$ hanya mampu pada memenuhi level $\mathrm{C} 4$ dan $\mathrm{C} 5$ sementara belum mampu memenuhi level C6. Selanjutnya dilakukan wawancara untuk mengetahui penyebab dan akar masalah sehingga siswa kategori sedang dan kategori rendah belum mampu memenuhi level C6 dengan rangkuman hasil wawancara yaitu siswa kategori sedang (S) memahami tentang apa yang 
diketahui dan apa yang ditanyakan dalam soal, namun siswa (S) tidak mampu meyelesaikan soal tersebut dengan operasi matriks dengan alasan bahwa tidak mampu merubah permasalahan tersebut kedalam bentuk matriks sehingga tidak diselesaikan dengan kaidah perkalian matriks dan siswa (S) berusaha menyelesaikan soal tersebut dengan mencari alternatif lain melalui perkalian biasa secara manual. Sedangkan siswa kategori rendah (R) sudah mampu mengetahui apa yang diketahui dan apa yang ditanyakan dalam soal, namun belum mampu menjawab soal level C6 dengan alasan bahwa soal tersebut susah, model soal berbeda dengan soal nomor 1 dan 2 sehingga tidak dimengerti, tidak mengerti cara menyelesaikannya, tidak tau rumus apa yang digunakan, dan menggunakan waktu yang lama untuk mengerjakannya sehingga soal nomor 3 sama sekali tidak dikerjakan.

Secara umum hasil penelitian ini menyimpulkan bahwa berpikir logis siswa dengan nilai rata-rata 60,19 atau berada pada kategori rendah, hasil penelitian ini sejalan dengan hasil penelitian (Mukhabibah, 2017) yang menemukan bahwa siswa kesulitan dalam berpikir logis dalam aspek berpikir deduktif dan induktif. Selanjutnya dalam kemampuan menyelesaikan soal HOTS diperoleh nilai rata-rata sebesar 71,41 atau berada pada kategori sedang, temuan ini sejalan dengan jasil penelitian yang juga menemukan bahwa kemampuan siswa dalam menyelesaikan masalah HOTS berada pada kategori sedang ditemukakan oleh (Mandini \& Hartono, 2018); (Ega et al., 2018); (Hanafi et al., 2019); (Intan et al., 2020); dan (Gammath \& Ralmugiz, 2020). Namun penelitian ini berbeda dengan hasil penelitian (Kusdianti et al., 2019) yang menemukan bahwa kemampuan siswa dalam menyelesaikan masalah HOTS berada pada kategori rendah.

Lebih lanjut, hasil penelitian tentang kemampuan menyelesaikan soal HOTS ditinjau dari kemampuan berpikir logis ditemukan bahwa siswa dengan kategori tinggi dalam kemampuan berpikir logis mampu memenuhi level C4, C5, dan C6. Hal tersebut berarti bahwa siswa dengan kategori tinggi (T) sudah mampu menganalisis suatu permasalahan dengan mencermati, memilah, mengidentifikasi, serta menentukan pola hubungan informasi. Demikian juga dalam hal mengevaluasi sudah mampu memeriksa dan mengeritik serta mengampil kesimpulan dalam hal penerimaan atau penolakan terhadap suatu solusi dari masalah yang ada. Siswa (T) juga sudah mampu mencipta dengan merumuskan, merencanakan, dan memproduksi suatu solusi atau keputusan dalam menyelesaikan masalah. Hasil penelitian ini sejalan dengan hasil penelitian (Pradestya et al., 2020) yang menyimpulkan bahwa siswa dengan kecerdasan logis matematis tinggi memiliki kemampuan kognitif yang baik pada tingkatan mengingat, memahami, menerapkan, menganalisis, dan mengevaluasi. (Hasyim \& Andreina, 2019) juga menemukan bahwa siswa dengan kemampuan HOTS tinggi mampu memenuhi indikator menganalisis, mengevaluasi, hingga mencipta. Demikian juga hasil penelitian yang dilakukan oleh (Santari et al., 2018); (Salsabila \& Sumardi, 2020); dan (Santoso \& Setyaningsih, 2020) telah menemukan hal yang sama dengan penelitian ini bahwa siswa berkemampuan tinggi memenuhi 3 indikator HOTS.

Temuan selanjutnya yaitu siswa dengan kategori sedang (S) hanya mampu 
memenuhi level C4 dan C5 sementara belum mampu memenuhi level C6. Hal ini bermakna bahwa siswa (S) sudah mampu menganalisis suatu permasalahan dengan mencermati, memilah, mengidentifikasi, serta menentukan pola hubungan informasi. Demikian juga dalam hal mengevaluasi sudah mampu memeriksa dan mengeritik serta mengampil kesimpulan dalam hal penerimaan atau penolakan terhadap suatu solusi dari masalah yang ada namun belum mampu mencipta dengan merumuskan, merencanakan, dan memproduksi suatu solusi atau keputusan dalam menyelesaikan masalah. Hasil penelitian ini sejalan dengan hasil penelitian (Pradestya et al., 2020) bahwa siswa dengan kecerdasan logis matematis sedang tidak bisa dikatakan memiliki kemampuan kognitif yang cukup. (Hajar \& Rahman, 2020) juga menemukan bahwa siswa dengan kemampuan tinggi lebih unggul dalam menyelesaikan soal HOTS dibanding dengan siswa kemampuan sedang dan rendah. Hasil penelitian lain yang relevan yaitu (Permana et al., 2020) bahwa siswa berkemampuan sedang belum mampu menemukan pola dari suatu gejala matematis.

Dalam penelitian ini juga ditemukan bahwa siswa dengan kategori sedang (R) hanya mampu memenuhi level $\mathrm{C} 4$ dan $\mathrm{C} 5$ sementara belum mampu memenuhi level C6. Kendala yang dihadapi yaitu siswa sudah mampu memahami soal namun mengalami kesulitan dan kendala dalam menerjemahkannya menjadi kalimat matematika, siswa belum mampu memberikan cara pandang terhadap suatu persoalan sehingga belum bisa mengeluarkan ide dan merancang solusi secara mandiri untuk menyelesaikan permasalahan dalam mengambil keputusan secara mandiri. Beberapa hasil penelitian relevan yang juga menemukan bahwa siswa masih kesulitan menyelesaikan soal dan permasalahan dengan C6 (mencipta) seperti dikemukan (Hidayati, 2019); (Purwanti, 2020); (Pratiwi, 2020); dan (Astuti \& Adirakasiwi, 2019).

Dengan demikian, maka temuan utama dalam penelitian ini adalah bahwa siswa dengan kategori tinggi (T) dalam kemampuan berpikir logis mampu memenuhi level C4 (menganalisis), C5 (mengevaluasi), dan C6 (mencipta), namun siswa dengan kategori sedang (S) dan kategori rendah $(\mathrm{R})$ hanya mampu pada memenuhi level C4 (menganalisis) dan C5 (mengevaluasi) dan secara umum siswa masih kesulitan memenuhi level C6 sehingga kemampuan C6 (mencipta) siswa masih tergolong rendah.

Implikasi penelitian ini memperlihatkan adanya perbedaan kemampuan menyelesaikan soal HOTS ditinjau dari kemampuan berpikir logis siswa. Hal ini dapat digunakan sebagai bahan pertimbangan dan masukan bagi guru dalam merencanakan dan melaksnakan proses pembelajaran agar memilih metode dan model pembelajaran yang dapat meningkatkan kemampuan berpikir logis siswa dan dapat meningkatkan hasil belajar siswa terutama dalam kemampuan menyelesaikan masalah HOTS.

\section{KESIMPULAN DAN SARAN}

Dari hasil penelitian dan pembahasan, maka ditarik simpulan bahwa siswa dengan kategori tinggi dalam hal berpikir logis mampu memenuhi kriteria C4, C5, dan C6 sedangkan siswa dengan kategori sedang dan rendah hanya mampu memenuhi kriteria C4 dan C5. Siswa masih kesulitan memenuhi level C6 
sehingga kemampuan C6 (mencipta) siswa masih tergolong rendah. Kendala yang dihadapi siswa (S) dan (R) dalam memenuhi aspek C6 yaitu siswa mengalami kesulitan dan kendala dalam menerjemahkan permasalahan kedalam kalimat matematika serta siswa belum mampu memberikan cara pandang terhadap suatu persoalan sehingga belum bisa mengeluarkan ide dan merancang solusi secara mandiri untuk menyelesaikan permasalahan dalam mengambil keputusan.

Akhirnya, untuk perbaikan dan tindaklanjut, maka disarankan kepada siswa untuk lebih sering melakukan latihan secara mandiri dalam menyelesaikan soal HOTS serta disarankan kepada guru agar terus membimbing dan berupaya meningkatkan kemampuan HOTS dan kemampuan berpikir logis siswa melalui berbagai cara seperti menerapkan pembelajaran yang berbasis HOTS, menyediakan media pembelajaran seperti buku paket, lebar kerja siswa, dan instrument yang berbasis HOT, serta mengikutkan siswa dalam kegiatankegiatan yang dapat meningkatkan kemampuan HOTS siswa. Selain itu, penelitian lanjutan disarankan mengkaji tentang strategi meningkatkan kemampuan HOTS siswa melalui optimalisasi kemampuan berpikir logis siswa dan melibatkan responden dari berbagai sekolah sehingga populasi lebih heterogen.

\section{DAFTAR PUSTAKA}

Aliyanti, A. P., Putri, O. R. U., \& Zukhrufurrohmah, Z. (2019). Analisis Kesalahan Representasi Simbolik
Mahasiswa Dalam Menyelesaikan Soal High Order Thinking Skill. AKSIOMA: Jurnal Program Studi Pendidikan Matematika, 8(3), 382. https://doi.org/10.24127/ajpm.v8i3.22 65

Annizar, A. M., Lestari, A. C., Sofiah, Khairunnisa, G. F., \& Maulyda, M. A. (2020). Proses Berpikir Inkuiri Dalam Menyelesaikan Masalah Higher Order Thinking Skills (Hots) Ditinjau dari Tingkat Kognitif. AKSIOMA: Jurnal Program Studi Pendidikan Matematika, 9(4), 11921204.

https://doi.org/https://doi.org/10.2412 7/ajpm.v9i4.3113

Astuti, N., \& Adirakasiwi, A. G. (2019). Analisis Kesulitan Siswa SMP dalam Menyelesaikan Soal HOTS ( Higher Order Thinking Skill ). Prosiding Seminar Nasional Matematika Dan Pendidikan Matematika Sesiomadika 2019, 415-426. https://doi.org/https://journal.unsika.a c.id/index.php/sesiomadika/article/vie w/2741

Budiarta, K., Harahap, M. H., Faisal, \& Mailani, E. (2018). Potret implementasi pembelajaran berbasis high order thinking skills (HOTS) di Sekolah Dasar Kota Medan. Jurnal Pembangunan Perkotaan, 6(2), 102111.

https://doi.org/http://ejpp.balitbang.pe mkomedan.go.id/index.php/JPP/articl e/view/47

Chinedu, C. C., \& Kamin, Y. (2015). Strategies for improving higher order thinking skills in teaching and learning of design and technology 
education. Journal of Technical Education and Training, 7(2), 35-43. https://doi.org/https://ir.unilag.edu.ng/ handle/123456789/6159

Permendiknas RI No. 22 Tahun 2006 tentang standar isi untuk satuan pendidikan dasar dan menengah, (2006).

https://doi.org/https://asefts63.files.w ordpress.com/2011/01/permendiknasno-22-tahun-2006-standar-isi.pdf

Driana, E., \& Ernawati. (2019). Teachers' Understanding And Practices In Assessing Higher Order Thinking Skill at Primary Schools. ACITYA Journal of Teaching \& Education, 1(2), 110-118. https://doi.org/https://doi.org/10.3065 0/ajte.v1i2.233

Ega, G., Firmansyah, B., \& Julia, N. (2018). Calon Guru Matematika Melalui Level Hots Marzano. EduMa, 7(2), 41-48.

Fitriana, S., Ihsan, H., \& Annas, S. (2015). Pengaruh efikasi diri, aktivitas, kemandirian belajar dan kemampuan berpikir logis terhadap hasil belajar matematika pada siswa kelas VIII SMP. Journal of EST, 1(2), 86-101.

Gammath, J., \& Ralmugiz, U. (2020). Kemampuan siswa smp kota kupang dalam menyelesaikan masalah hots matematika. Jurnal Gammath, 5(1), 38-43.

https://doi.org/https://core.ac.uk/down load/pdf/322517377.pdf

Hajar, M. N., \& Rahman, A. (2020). Analisis Kemampuan Siswa Dalam Menyelesaikan Soal-Soal HOTS Tipe PISA Ditinjau dari Prestasi Belajar
Matematika Sekolah. 1(2), 85-96.

Hanafi, M., Wulandari, K. N., \& Ni'mah. (2019). Analisis Kemampuan Siswa Dalam Menyelesaikan Soal High Order Thinking Ditinjau Dari Kemampuan Awal Matematis Siswa. Seminar Nasional Penelitian Pendidikan Matematika (SNP2M) 2019 UMT, 6(2), 46-56. https://doi.org/10.31980/mosharafa.v 6i2.313

Hasyim, M., \& Andreina, F. K. (2019). Analisis High Order Thinking Skill (Hots) Siswa Dalam Menyelesaikan Soal Open Ended Matematika. FIBONACCI: Jurnal Pendidikan Matematika Dan Matematika, 5(1), 55.

https://doi.org/10.24853/fbc.5.1.55-64

Hidayati, D. N. (2019). Analisis Kesalahan Penyelesaian Soal Cerita Matematika Bertipe Hots Berdasarkan Teori Newman Pada Siswa Kelas V SD. University of Muhammadiyah Malang.

Intan, F. M., Kuntarto, E., \& ... (2020). Kemampuan Siswa dalam Mengerjakan Soal HOTS (Higher Order Thinking Skills) pada Pembelajaran Matematika di Kelas V Sekolah Dasar. JPDI (Jurnal ... https://doi.org/http://dx.doi.org/10.26 737/jpdi.v5i1.1666

Kirchner, M. D. (2017). Teaching the Industrial Internet of Things Preparing Students and Learners for Industry 4 . 0. September, 0-17.

Konda, L. (2020). What is the Purpose of Learning Math. https://sites.google.com/site/mathofgl 
endale/what-is-the-purpose-oflearning-math

Kusdianti, I., Sitompul, S. S., \& ... (2019). Analisis Kemampuan Peserta Didik dalam Menyelesaikan Soal HOTS Kelas XI SMAN 2 Sungai Raya. Jurnal Pendidikan Dan ....

Kusuma, M. D., Rosidin, U., Abdurrahman, A., \& Suyatna, A. (2017). The Development of Higher Order Thinking Skill (Hots) Instrument Assessment In Physics Study. IOSR Journal of Research \& Method in Education (IOSRJRME), 07(01), 26-32. https://doi.org/10.9790/73880701052632

Lewis, A., \& Smith, D. (2011). Defining Higher Order Thinking. Theory Into Practice, 32(3), 131-137. https://doi.org/10.1080/00405849309 543588

Mandini, G. W., \& Hartono, H. (2018). Analisis kemampuan menyelesaikan soal HOTS model TIMSS dan kepercayaan diri siswa sekolah menengah pertama. Pythagoras: Jurnal Pendidikan Matematika, 13(2), 148-157. https://doi.org/10.21831/pg.v13i2.212 34

Mardhiyyah, L. A., Rusilowati, A., \& Linuwih, S. (2016). Pengembangan Instrumen Asesmen Literasi Sains Tema Energi. Journal of Primary Education, 5(2), 147-154.

Misri, M. A., \& Kamelia, N. R. (2018). Pengembangan Instrument Test Materi Matriks berdasarkan konsep HOT. Beta: Jurnal Tadris
Matematika, $\quad 11(2), \quad 1-12$. https://doi.org/10.20414/betajtm.v9i2. XXX

Misrom, N. S., Abdurrahman, M. S., Abdullah, A. H., Osman, S., Hamzah, M. H., \& Fauzan, A. (2020). Enhancing students' higher-order thinking skills (HOTS) through an inductive reasoning strategy using geogebra. International Journal of Emerging Technologies in Learning, 15(3), 156-179. https://doi.org/10.3991/ijet.v15i03.98 39

Mukhabibah, M. (2017). Analisis Kemampuan Berpikir Logis Matematis dalam Pembelajaran Discovery Learning Materi Aturan Pencacahan Kelas XI SMA Bustanul Ulum Nu Bumiayu Berdasarkan Gaya Belajar Siswa. Repositori Universitas Peradaban.

Nisa, N. A. K., Widyastuti, R., \& Hamid, A. (2018). Pengembangan Instrumen Assesment Higher Order Thinking Skill (HOTS) Pada Lembar Kerja Peserta Didik Kelas VII SMP. Prosiding Seminar Nasional Matematika Dan Pendidikan Matematika, 3(3), 543-556.

Permana, N. N., Setiani, A., \& Nurcahyono, N. A. (2020). J urnal Pengembangan Pembelajaran Matematika (JPPM) / Vol II No 1 Februari 2020. Jurnal Pengembangan Pembelajaran Matematika, II(1), 20 26. https://doi.org/http://202.0.92.5/sainte $\mathrm{k} / \mathrm{jpm} /$ article/view/2077

Pradestya, R., Imswatama, A., \& Balkist, 
P. S. (2020). Analisis Kemampuan Kognitif pada Langkah-Langkah Pemecahan Masalah Ditinjau Dari Kecerdasan Logis- Matematis. Pasundan Journal of Research in Mathematics Learning and Education, 5(2), 73-92. https://doi.org/http://dx.doi.org/10.23 969/symmetry.v5i1.1723

Pratiwi, C. D. (2020). Analisis Kemampuan Mahasiswa dalam Menyelesaikan Soal Hots (High Order Thinking Skills) Pada Tingkatan C6. Math Didactic: Jurnal Pendidikan Matematika, 6(3), 287295.

https://doi.org/https://doi.org/10.3365 4/math.v6i3.1024

Priatna, N., \& Yuliardi, R. (2019). Pembelajaran Matematika untuk Guru SD dan Calon Guru SD. PT Remaja Rosdakarya.

Purwanti, S. (2020). Analisis kemampuan mahasiswa dalam menyelesaikan soal IPA tipe HOTS. Jipva, 4, 93-101. https://doi.org/https://doi.org/10.3133 1/jipva.v4i1.1102

Purwanto, N. (2012). Prinsip-Prinsip dan Teknik Evaluasi Pengajaran. PT Remaja Rosdakarya.

Retnawati, H., Djidu, H., Kartianom, Apino, E., \& Anazifa, R. D. (2018). Teachers' knowledge about higherorder thinking skills and its learning strategy. Problems of Education in the 21st Century, 76(2), 215-230. https://doi.org/10.33225/pec/18.76.21 5

Rochman, S., \& Hartoyo, Z. (2018). Analisis High Order Thinking Skills (
Hots ). SPEJ (Science and Physics Education Journal), 1(2).

Salsabila, N. Q., \& Sumardi. (2020). Kemampuan Siswa Dalam Menyelesaikan Soal Higher Order Thinking Skills (HOTS).

Santari, D. M., Ningsih, S., \& Jana, P. (2018). Analisis High Order Thinking Skills Mahasiswa dalam Menyelesaikan Soal Uraian Ditinjau dari Kemampuan Awal Matematik. Universitas PGRI Yogyakarta, 1-11.

Santoso, R. M., \& Setyaningsih, N. (2020). Literasi Matematika Siswa dalam Menyelesaikan Soal HOTS Bentuk Aljabar Berdasarkan Kemampuan Matematika. Konferensi Nasional Penelitian Matematika Dan Pembelajarannya (KNPMP) V, 6271.

Saraswati, P. M. S., \& Agustika, G. N. S. (2020). Kemampuan Berpikir Tingkat Tinggi Dalam Menyelesaikan Soal HOTS Mata Pelajaran Matematika. Jurnal Ilmiah Sekolah Dasar, 4(2), 257.

https://doi.org/10.23887/jisd.v4i2.253 36

Setiawan, A., Malik, A., Suhandi, A., \& Permanasari, A. (2018). Effect of Higher Order Thinking Laboratory on the Improvement of Critical and Creative Thinking Skills. IOP Conference Series: Materials Science and Engineering, 306(1). https://doi.org/10.1088/1757899X/306/1/012008

Shidiq, A. S., Masykuri, M., \& Susanti, E. (2015). Analisis Higher Order Thinking Skills (HOTS) 
DOI: https://doi.org/10.24127/ajpm.v10i2.3480

Menggunakan Instrumen Two-Tier Multiple Choice Pada Materi Kelarutan Dan Hasil Kali Kelarutan Untuk Siswa Kelas Xi Sma N 1 Surakarta. Prosiding Seminar Nasional Pendidikan Sains, November, 2015-2159.

Suhirman, Y., Muliadi, A., \& Prayogi, S. (2020). The effect of problem-based learning with character emphasis toward students' higher-order thinking skills and characters. International Journal of Emerging Technologies in Learning, 15(6), 183-191.

https://doi.org/10.3991/IJET.V15I06. 12061

Sulaiman, Muniyan, V., Diwiyah Madhvan, Raidah Hasan, \& Suzieleez Syrene Abdul Rahim. (2017). Implementation of higher order thinking skills in teaching of Science. International Research Journal of Education and Sciences, 1(1), 1-3.

Supendi, A., \& Nurjanah. (2019). Society 5 . 0 : Is It High-Order Thinking? Global Perspective on 21st Elementary Education, 2(1), 10541059.

Suratmi, Laihat, Asnimar, \& Ela Okta Handini. (2020). Teachers Understanding of HOTS Based Assessment in Elementary Schools. The 2nd International Conference on Elementary Education, 2(23), 11571164.

Sutrisno, S., Dardiri, A., \& Winahyo, A. E. (2020). Opinions about the use of higher order thinking skills in general, vocational, and academic education learning in indonesia. In 4th International Conference on Vocational Education and Training, ICOVET 2020 (pp. 101-106). https://doi.org/10.1109/ICOVET5025 8.2020 .9230234

Tan, S. Y., \& Halili, S. H. (2015). Effective Teaching of Higher-Order Thinking (HOT) in Education. The Online Journal of Distance Education and E-Learning, 3(2), 41-47.

Tanujaya, B., Mumu, J., \& Margono, G. (2017). The Relationship between Higher Order Thinking Skills and Academic Performance of Student in Mathematics Instruction. International Education Studies, 10(11), 78 . https://doi.org/10.5539/ies.v10n11p78

Toheri, \& Muchyidin, A. (2019). Panduan Pelatihan Penyusunan soal HOTS Matematika. CV. Confident.

Tonra, W. S., Budiarto, M. T., Masriyah, \& Tonra, W. S. (2019). Profile of High Order Thingking Skill ( HOTS ) of Junior High School Students , Grade 8 in Solving Linear Equation System Problems Based on Kinesthetic and Visual Learning Styles. International Journal of Trends in Mathematics Education Research, 2(4), 212-214. https://doi.org/10.33122/ijtmer.v2i4.1 39

Wahyuddin. (2013). Pengaruh Kemampuan Berpikir Logis dan 
DOI: https://doi.org/10.24127/ajpm.v10i2.3480

Kemampuan Verbal Terhadap

Kemampuan Menyelesaikan Soal

Cerita Matematika Melalui

Kemampuan Penalaran dan

Komunikasi pada Siswa. Universitas

Negeri Makassar.

Widana, I. W., Parwata, I. M. Y., Parmithi, N. N., \& Jayantika, I. G. A. T. (2018). Higher Order Thinking Skills Assessment towards Critical Thinking on Mathematics Lesson. International Journal of Social Sciences and Humanities (IJSSH), 2(1), 24-32. https://doi.org/10.29332/ijssh.v2n1.74

Yee, M. H., Jailani, M. Y., Widad, O., Razali, H., Tee, T. K., \& Mohaffyza, M. M. (2015). The Effectiveness of Higher Order Thinking Skills for Generating Idea among Technical Students. Recent Advances in Educational Technologies, 204, 113118.

Zaiyar, M., \& Rusmar, I. (2020). Students' Creative Thinking Skill in Solving Higher Order Thinking Skills (HOTS) Problems. Al-Jabar: Jurnal Pendidikan ..., 11(1), 111-120. https://doi.org/https://doi.org/10.2404 2/ajpm.v11i1.5935 